\title{
SLIP SURFACE IN A CLAY-SAND MIXTURE SLOPE TEST USING SCALED LABORATORY MODELS
}

\author{
Julita Andrini Repadi ${ }^{1}$, Fathol Bari ${ }^{2}$, Junaidi ${ }^{3}$, Febrin Anas Ismail ${ }^{4}$, Andriani ${ }^{5}$ and ${ }^{*}$ Abdul Hakam ${ }^{6}$ \\ ${ }_{1,2,3,4,5,6}$ Engineering Faculty, Andalas University, Indonesia \\ *Corresponding Author, Received: 15 Mar. 2021， Revised: 14 July 2021, Accepted: 28 July 2021
}

\begin{abstract}
Determining the assumed failure slip surface is the most important phase in slope stability analysis. Determining the slip surface is still a basic problem in practical engineering. The right assumed slip surface has never been entirely resolved. The focus of this study is the determination of the slip surface on a slope made from a mixture of clay and sand. The slope materials were created in 2 combinations, namely Combination- 1 consisting of $30 \%$ clay $+70 \%$ sand, and Combination- 2 consisting of a mixture of $50 \%$ clay $+50 \%$ sand. The experimental works were carried out using a glass box measuring $110 \mathrm{~cm}$ x $40 \mathrm{~cm} \mathrm{x} 10 \mathrm{~cm}$ with a thickness of $10 \mathrm{~mm}$, a pressing device, a proving ring, dial gauges and colored marks. The applied load on the model was uniformly distributed. The Fellenius method was adopted to compare to the experiment results. The Fellenius method was carried out using trial and error at 60 coordinate points. The analysis results using the Fellenius method indicated a single critical slip surface at a single coordinate point. The results of the slip surface using the experimental work showed that there was a combination of a linear and rotational slip surfaces. This is in contrast to the Fellenius slip surface, which was rotational.
\end{abstract}

Keywords: Slip surface, Experimental, Clayey sand, Slope stability

\section{INTRODUCTION}

Based on its geographical, demographic, and climatology aspects, Indonesia is a disaster-prone country. Indonesia consists of more than 16 thousand islands located between the Asian and Australian continents, and between the Indian and Pacific oceans. This covers 3 continental plates and 127 active volcanoes. Those conditions cause frequent landslides [1].

West Sumatra is one of the regions in Indonesia that has hills with dangerous slopes. The geology and topography of West Sumatra means that this region is vulnerable to landslides [2]. Landslides are a problem in cities and villages [3], in addition to harming constructions and the altered land above and below the slope. One of the important factors in the analysis of landslides is the slip surface [4]. The slip surface is the border area on which the mass of the landslide moves [5-7]. Determining the slip surface location and geometry is an important indicator in slope safety $[8,9]$.

This research looked for slip surfaces using the Improved Whale Optimization Algorithm (IWOA) compared to the Whale Optimization Algorithm (WOA) and Particle Swarm Optimization (PSO) methods. The comparison showed that the IWOA method is more accurate than the WOA and PSO methods [9]. The slip surface of a slope can be divided into circular and non-circular forms as well as linear and irregular patterns [10]. The slip surface must be assessed from the top to the bottom of the slope [11].

The safety factor of slopes is estimated using the ratio of acting disturbed forces related to the slip surface. Additional loads on slopes, such as buildings and landfills due to human activities, may increase the forces acting on the soil, which causes landslides [8].

Landslide prevention and mitigation can be conducted in areas that have the potential for landslides in order to reduce the risk and maximize the land use surrounding the slope [9]. Landslide mitigation can be done by increasing the slope safety factors in ways such as the use of technological developments. More researchers use numerical methods than experimental ones due to them being time-consuming and expensive [12].

The shape of the slip surface in the Limit Element Method (LEM) is assumed to be a circular arc in most LEM executions [13-18]. The researchers reported on the comparison study conducted on the three methods, namely the LEM Bishop method, the virtue method (SRM), and the enhanced limit strength (ELSM) method in order to find the slip surface and to estimate the safety factors. It was found that the SRM has the disadvantage of using finite elements while also being time-consuming [13]. The search for the critical surface using the Max-Min ant colony optimization algorithm (MMACOA) is one of the best performing algorithms for use in several optimization problems. This was then compared to the LEM of the Bishop, Jambu, Spencer and Morgenstern methods [19]. Twoand 3-dimensional critical slip surfaces can also be generated using automatic extracted scatter [20].

In the field, the slip surface on the tuff can be conducted using 5 methods (geophysical exploration, logging, tracking, mechanical search, and numerical) to obtain 5 possible slip surface estimations. Even in the field, slip surfaces are still difficult to determine 
[21]. The determination of the slip surface in fracture zone landslides can be done through observations, geophysical measurements and the digital imaging analysis of specific oriented core samples [7].

Based on the previous research, experimental research carried out to determine the slip surface is infrequent. In this study, the determination of the slip surface was conducted using scaled laboratory experiments. The advantage of the experimental method is that each grain movement can be recorded and the slip surface shape can be seen clearly and drawn accurately. For comparison study purposes, safety factor analyses were conducted based on the determination of the slip surface using the Fellenius method.

\section{SAFETY FACTOR ANALYSIS}

The Fellenius method for determining the slip surface in this study was adopted and then compared with the experimental results. The safety factors of the slope were estimated using the following steps:

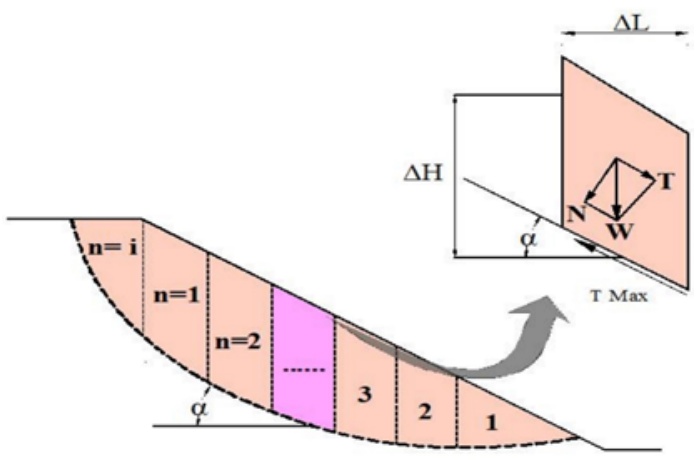

Fig.1 Slip circle for the Fellenius method

Fig.1 shows the normal force $(\mathrm{N})$ and tangential force (T) acting on each of the slices. This is calculated as follows:

$$
\begin{aligned}
& N=W \cos \alpha \\
& T=W \sin \alpha
\end{aligned}
$$

The resistance force acting on the collapse plane is then:

$$
T_{\text {max }}=c \Delta A+N \operatorname{tg} \varphi
$$

The formula above is similar to the failure limit equation in the normal-shear stress graph as shown in Fig. 2. The safety factor of the slip circle can then be calculated as:

$S F=\frac{\text { Resisting Force }}{\text { Driving Force }}$

$$
S F=\frac{1}{\Sigma_{i} W_{i} \operatorname{sina} a_{i}} \sum_{i}\left(c_{i} \Delta A+W \cos a_{i} \tan \varphi_{i}\right)
$$

where:

$$
\begin{aligned}
& c_{i}, \quad \text { : Soil cohesion } \\
& \Delta A: \text { Area } \\
& W_{i} \text { : Soil weight } \\
& a_{i} \quad \text { : The angle of inclination } \\
& \varphi_{i} \quad \text { : The angle of shear in slopes }
\end{aligned}
$$

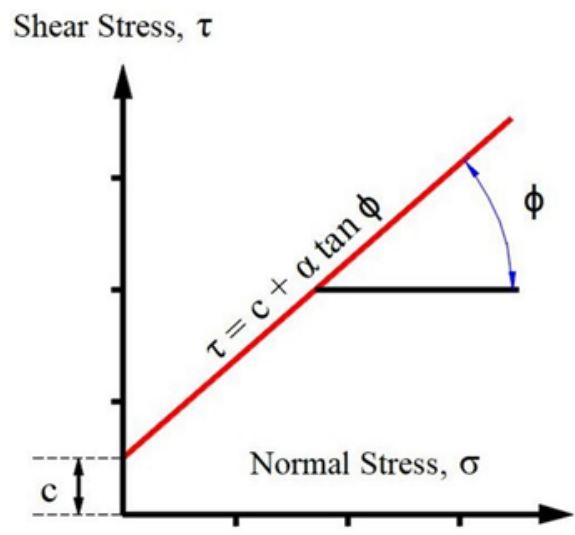

Fig.2 Failure line

The Fellenius method has been used for years by researchers [3]. The calculation steps as pat of the Fellenius method are as follows:

1. Draw the slope conditions using a good scale

2. Estimate the center point and slip surface through trial and error

3. Divide the slope into segments

4. Determine the width, weight and angle of each of the segments, then draw the potential intersection of the slip surface with a vertical line

5. Calculate the value of the safety factor

6. Steps 1 to 5 are repeated to get the minimum safety factor

For public works and practical purposes in Indonesia, the minimum slope safety factor can be adopted based on the value shown in Table 1:

Table 1 Slope minimum safety factor [3]

\begin{tabular}{llc}
\hline Risk & Load Conditions & SF \\
\hline High & With an & 1,2 \\
& earthquake & \\
& No earthquake & 1,8 \\
Intermediate & With an & 1,3 \\
& earthquake & \\
& No earthquake & 1,5 \\
Low & With an & 1,1 \\
& earthquake & \\
& No earthquake & 1,25
\end{tabular}




\section{EXPERIMENTAL WORK}

\subsection{Material Preparation}

In the laboratory experiments, the clay soil samples were taken from around the area of Andalas Padang University The original color of the clay was light brown. The sands were taken from Padang city in West Sumatra. The sand is relatively fine with a gray color.

Firstly, the sand was washed to remove any sludge and organic content. Then it was mixed with the clay into the designated combinations.

$>$ First combination $=70 \%$ sand $+30 \%$ clay material (Fig. 3). It can be seen that the color of the mixed clay-sand is dominated by the gray sand.

$>$ Second combination $=50 \%$ sand $+50 \%$ clay materials (Fig. 4). It can be seen that the color of the mixture is more light brown than gray. This indicates the domination of the clay in the mixture.

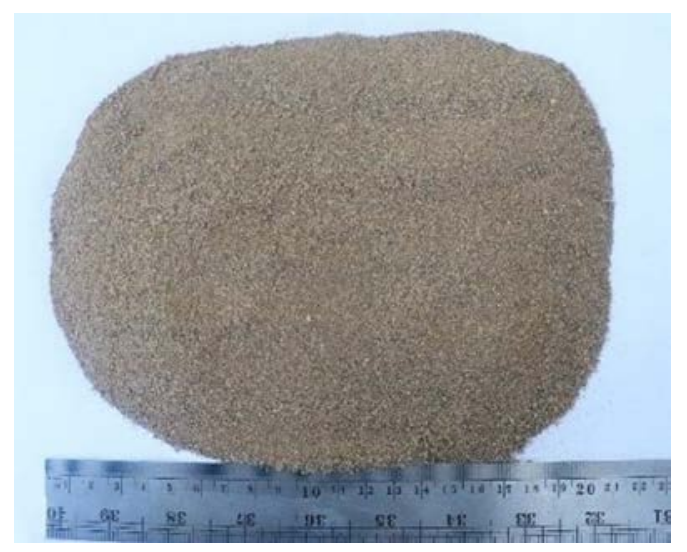

Fig. 3 Combination of $70 \%$ sand $+30 \%$ clay

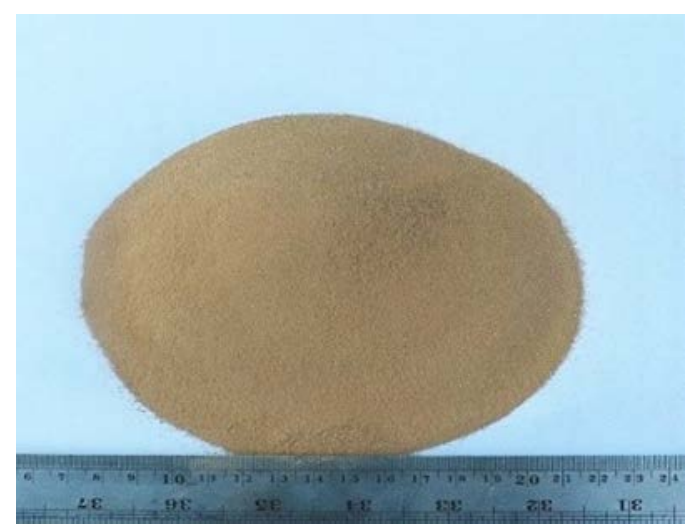

Fig. 4 Combination of $50 \%$ sand $+50 \%$ clay
The properties of the mixed soil combinations in this study are shown in Table 2.

Table 2 Soil properties

\begin{tabular}{|c|c|c|}
\hline Items & Combination 1 & Combination 2 \\
\hline \multicolumn{3}{|c|}{ Geometric of slopes } \\
\hline $\begin{array}{l}\text { Slope height } \\
\text { (H) }\end{array}$ & $18 \mathrm{~cm}$ & $18 \mathrm{~cm}$ \\
\hline $\begin{array}{l}\text { Slope width } \\
\text { (B) }\end{array}$ & $63,21 \mathrm{~cm}$ & $63 \mathrm{~cm}$ \\
\hline $\begin{array}{l}\text { Slope angle } \\
(\alpha)\end{array}$ & $30,82^{\circ}$ & $30^{\circ}$ \\
\hline \multicolumn{3}{|c|}{ Direct shear test } \\
\hline $\begin{array}{l}\text { Friction } \\
\text { angle }(\Phi)\end{array}$ & $30.82^{\circ}$ & $30.20^{\circ}$ \\
\hline $\begin{array}{l}\text { Total Units } \\
\text { weight (y) }\end{array}$ & $14.8 \mathrm{kN} / \mathrm{m}^{3}$ & $14.5 \mathrm{kN} / \mathrm{m}^{2}$ \\
\hline Cohesion (c) & $4.2 \mathrm{kN} / \mathrm{m}^{2}$ & $5.1 \mathrm{kN} / \mathrm{m}^{2}$ \\
\hline
\end{tabular}

\subsection{Equipment Preparation}

The sample glass box measured $110 \mathrm{~cm} \mathrm{x} 10 \mathrm{~cm}$ x $40 \mathrm{~cm}$ with a thickness of $10 \mathrm{~mm}$.

There was also a pressure frame measuring $65 \mathrm{~cm}$ high $x 50 \mathrm{~cm}$ wide. In the upper center of the frame, the crank was placed to allow the applied load's value to be read using the proving ring. The movement of the slope was read using the dial gauge. Under the proving ring, there was a stabilizing iron ball and a loading plate with dimensions of $20 \mathrm{~cm}$ x $9.5 \mathrm{~cm} \times 1$ $\mathrm{cm}$. The distributed load was applied until the slope collapsed.

The mixed clay-sand material was put into the glass box to make a slope with an angle $(\alpha)$ that was the same as that of the internal shear angle $(\Phi)$. For every distance of $2.5 \mathrm{~cm}$ in the horizontal and vertical, the material sample was colored in order to determine the movement of the soil grains. The arrangement of the experiment was as shown in Fig 5.

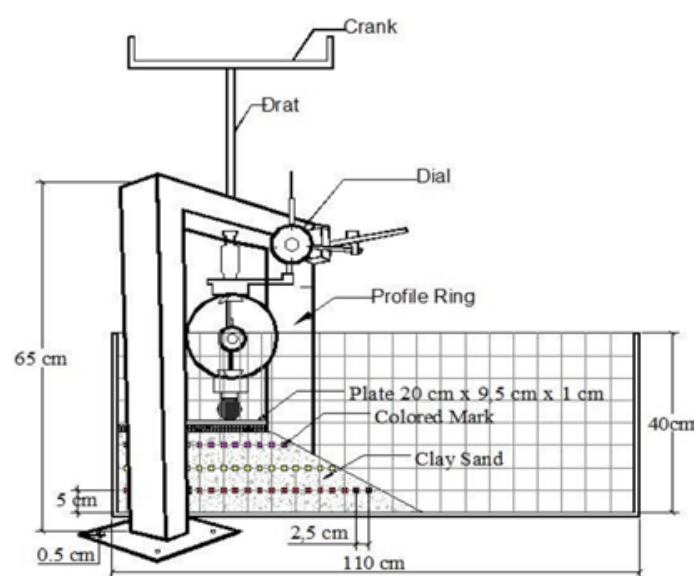

Fig.5 The arrangement experimental work 


\section{RESULTS AND DISCUSSION}

\subsection{Safety Factor}

Using trial analyses, the minimum safety factor of the slope was obtained. This trial circles with the minimum safety factor values were taken as the critical slip surface. It was found that the critical slip surfaces between combination 1 and combination 2 using the Fellenius method had the same shape and depth. Both of the critical surfaces of combination 1 and combination 2 decreased in trial number 3 in the analysis as shown in Figs. 6 and 7 respectively. The safety factor values of the analyses are as detailed in Table 3.

Table 3 The safety factor combination 1 and 2

\begin{tabular}{ccc}
\hline Items & Combination 1 & Combination 2 \\
\hline Clay \% & 30 & 70 \\
Sand \% & 50 & 50 \\
SF & 1,47 & 1,37 \\
\hline
\end{tabular}

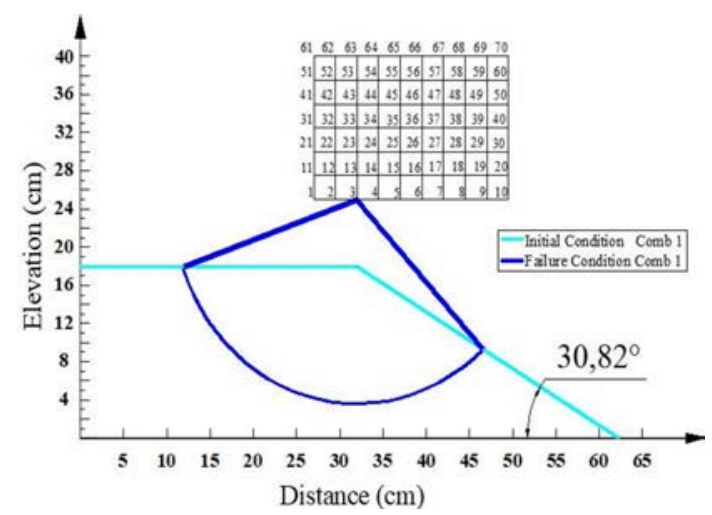

Fig.6 Critical slip surface (combination 1)

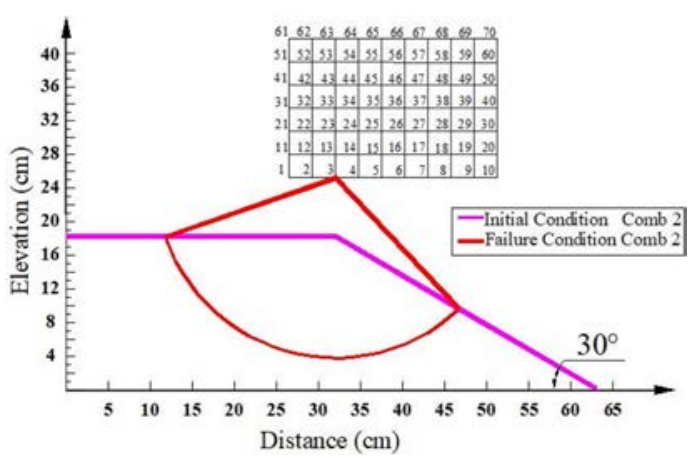

Fig.7 Critical slip surface (combination 2)

\subsection{Experiment Results}

First, the test was conducted for combination 1 with a ratio of $70 \%$ sand and $30 \%$ clay (Fig.8). The slope height was $18 \mathrm{~cm}$. In the slope during the preparation, for every distance of $2.5 \mathrm{~cm}$ horizontally and $5 \mathrm{~cm}$ vertically, colored marks were placed. These marks were very important a as part of determining the movement of the soil particles. The marks were made of wooden sticks with the length a bit less than the width of the glass box. This meant that it can move freely with the soil particles without any friction from the box.

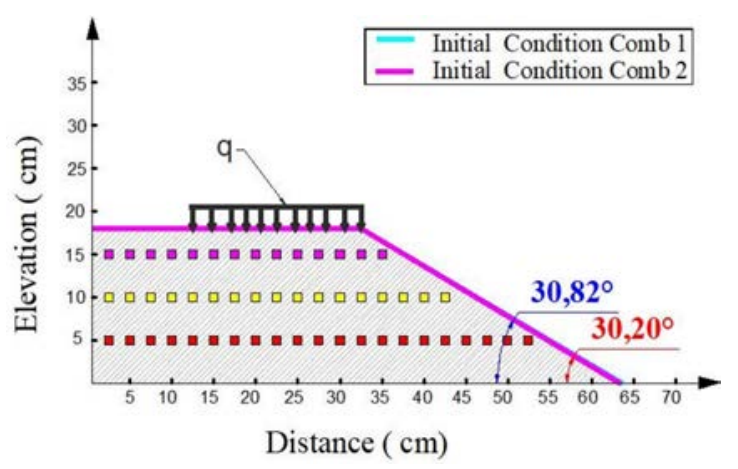

Fig.8 Slope initial conditions (combination 1)

On the top of the slope models, the distributed load was applied by pushing the plate downward. The value of the applied load was monitored using the proving ring. The load was applied to the slope until the slope fully collapsed. The value of the applied load was referred to as the maximum load of the slope. The final condition of the slope made of $70 \%$ sand and $30 \%$ clay material is shown in Fig. 9.

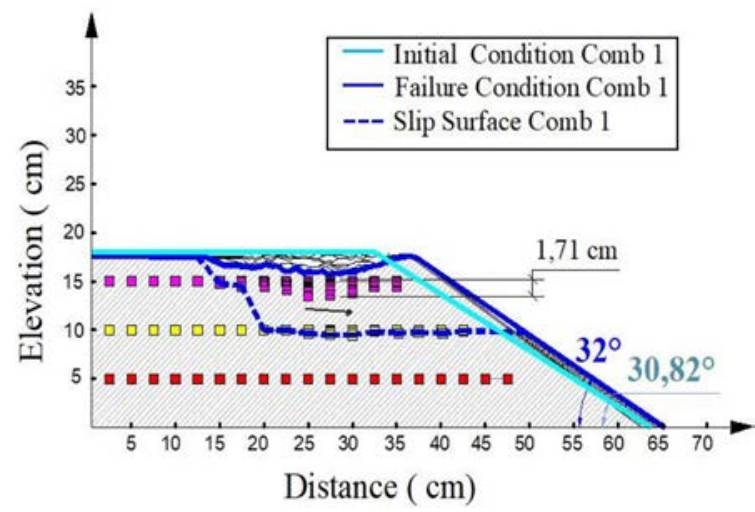

Fig.9 Final slope condition (combination 1)

Fig. 9 shows the maximum settlement of $1.71 \mathrm{~cm}$ on the top of slope. This is about $9.5 \%$ of the slope's height. There was also a horizontal movement of 1.53 $\mathrm{cm}$ which is $2.4 \%$ of the length of the slope. Beside the movement, the slope shape also shifted from the original angle of $30.82^{\circ}$ to an angle of $32^{\circ}$ in the final condition.

Second, the preparation of the slope for combination 2 was the same as it was for combination 
1. The only difference between the two slopes was the angle of the slope, as it was $30^{\circ}$ for combination 2 . The schematic model of the slope is shown in Fig. 10.

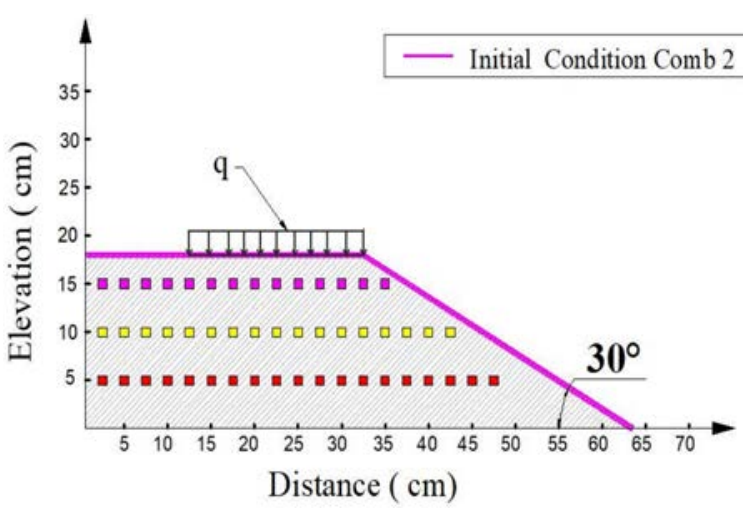

Fig.10 Initial slope condition (combination 2)

In order to record the movement of the material in the slope, the load was applied by pushing the loading plate on the top of the slope.

This applied load was increased until the slope fully collapsed which is indicated by the lower value of the proving ring. The initial and final condition of the combination 2 slope is shown in Fig 11.

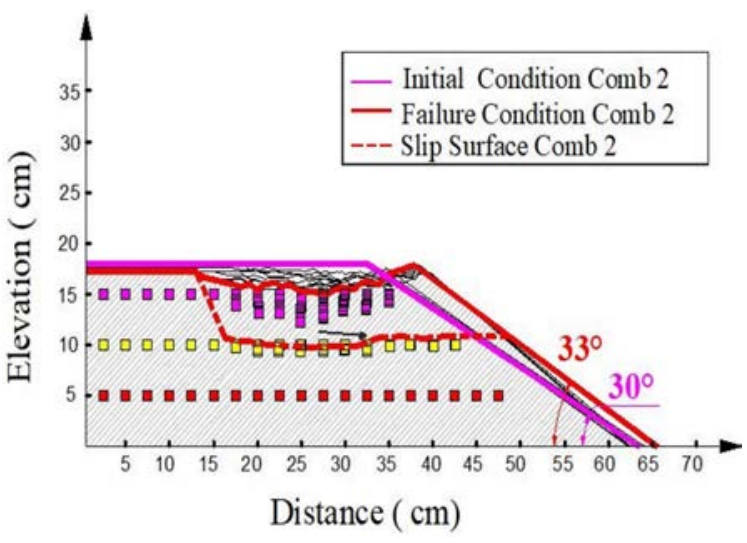

Fig.11 Final slope condition of combination 2

For slope combination 2, it can be seen that the top of the slope had a settlement of $2.81 \mathrm{~cm}$ which is about $15.6 \%$ of the initial slope height. The maximum horizontal movement was $2.07 \mathrm{~cm}$ which is equal to $3.2 \%$ of the original slope length. The slope angle shifted from $30 \mathrm{o}$ to $33 \mathrm{o}$. The final slope angle was also steeper than its original one.

In order to compare combination 1 and 2, both slopes were plotted together as shown in Fig. 12. It shows that the difference in the slope angle was only 0.62 degrees. Given the size of the different, it can be said that the original slopes are the same.

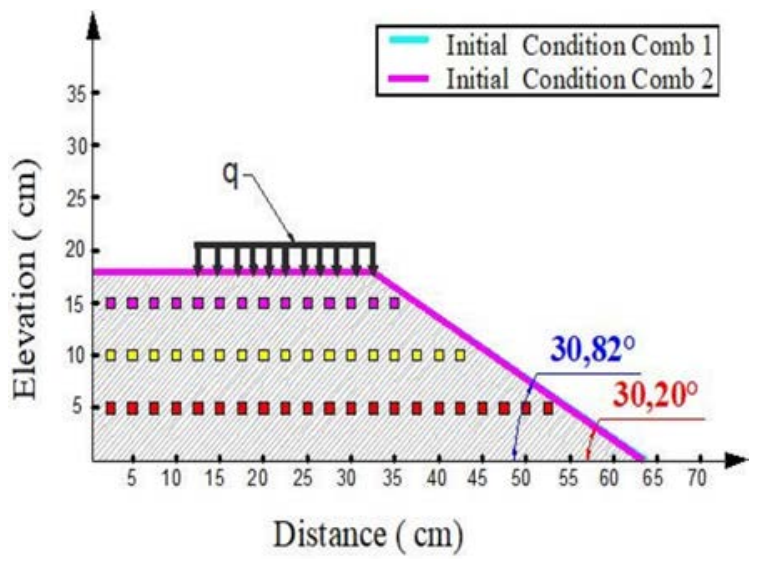

Fig.12 Slopes in their initial condition

The final conditions of the combination 1 and 2 slopes were then plotted together as shown in Fig. 13. It shows the differences in the slope angle movement. The slopes generally moved in the same way but with different values.

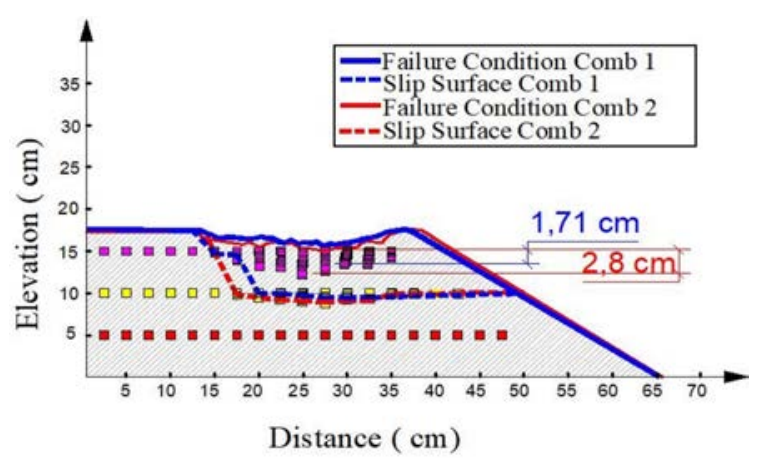

Fig.13 Slopes in their final condition

The pattern of the slip surface of the slopes is a combination of linear and rotational. Besides settling into the vertical direction, the slopes also moved in the horizontal direction which can be clearly observed. The horizontal shift of combination 2 was greater than that of combination 1 .

The comparison of the critical slip surface according to the Fellenius method with the experimental results for combination 1 and 2 is shown in Fig. 14. The differences in the slip surface pattern between them can be seen. However, it can also be seen that the starting points and ending points of the slip surfaces between the Fellenius method and the experiment results are almost the same. The starting point of the slip surface is at the edge of the distributed loads given in the Fellenius method which are the same as the applied loads in the experiment. Even thought it has different slip path afterward, the location of the ending point is almost the same.

If the drawn circle of the Fellenius method was taken to be the reference point, then the slip surfaces 
of the slopes would go from the edge of the distributed load on the top and through the body of the slopes. The slip surfaces then stop at the point in at a distance so long as the distributed load is at the steep part of the slope (Fig. 14).

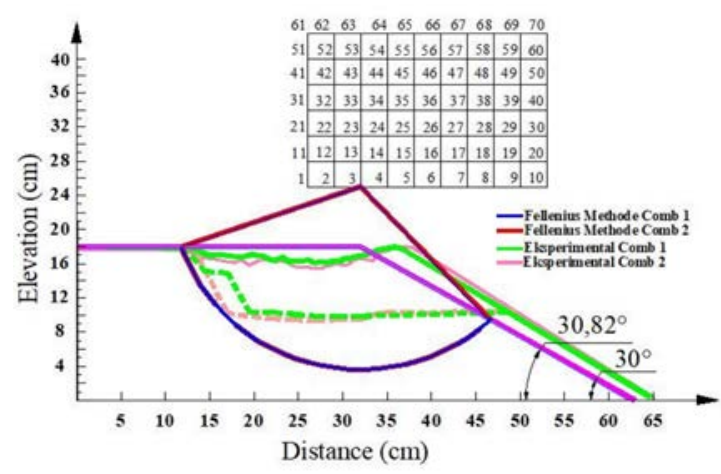

Fig.14 Slip surface according to both the Fellenius method and the experiment results

It also can be seen that the critical slip surface of the Fellenius method resulted in a larger soil mass moving in comparison to the experimental results. The moved soil mass in the experiment is about two thirds of the Fellenius soil mass. The effect of the size of the moved soil mass was deeply analyzed in this study. It may contribute to the stability of the slope, especially when there is an applied load at the top of said slope.

Figure 15 shows the load versus settlement relationship for the experimental slopes. The curves were found to have a similar pattern where the loads increased for the deeper settlement. However, the slope in combination 2 resulted in a greater settlement and maximum load compared to the combination 1 . Combination 1 had a maximum applied load of $9665,78 \mathrm{~kg} / \mathrm{m} 2$. Combination 2 had a maximum applied load that was almost one and a half times that of combination 1 of $12055,12 \mathrm{~kg} / \mathrm{m} 2$. The difference in the maximum applied load may be contributed to by the cohesion parameters of the soil.

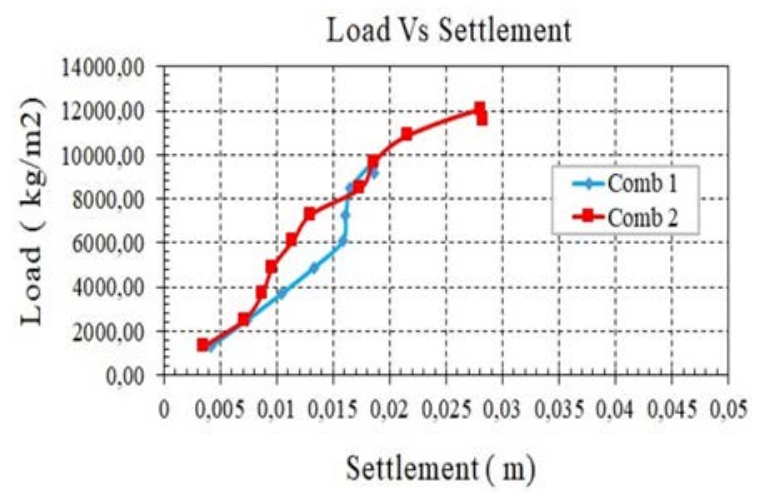

Fig.15 The relationship between load vs. settlement

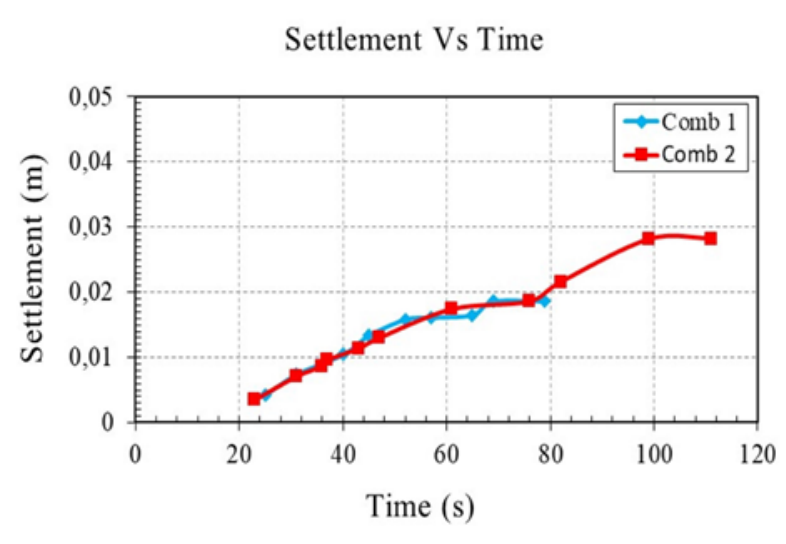

Fig.16 The relationship between settlement vs time

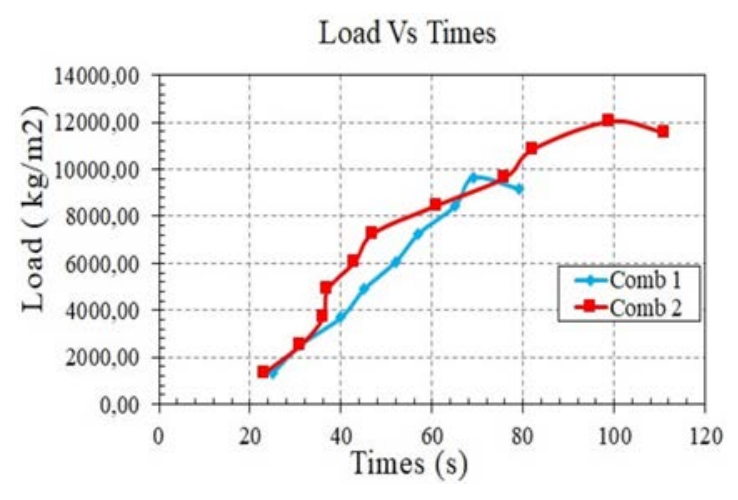

Fig.17 The load vs time relationship

Figs. 16 and 17 show the time recorded during the application of the loads related to the settlement. It can be seen that the graphs look different between the 2 combinations but they have the same trend. This indicates that the movement of the soil in the slope distributes the applied load at the same time. However, after 80 seconds, the applied load on slope combination 2 was continued whereas it stopped for slope combination 1 .

\section{CONCLUSIONS}

The experimental tests for the scaled slope model conducted in the laboratory in this study were successfully completed. The slopes were made from 2 combinations of clay and sand material. Based on the results of the tests, it can be concluded that the slip pattern of the loaded slope does not have regular pattern. The slip surfaces of the 2 slopes combine linear and rotational directions. They start going from the edge of the top of the applied load relatively vertical in a downward manner and then change to a lateral direction at the steepest point of the slopes.

Compared to the Fellenius method, the slip surface pattern of the experiment results are not the same. The soil movement in the experimental result is, however, still in the area predicted by the Fellenius 
method. The movement areas in the experiment were less than the critical area determined in the Fellenius method.

Since the slope using combination 2 was made from soil with more clay, it also had higher cohesion parameters. The internal friction angles of the two combinations were almost the same. It also can be concluded that the higher the cohesion of the soil, the higher the applied load can be on the top surface of the slope.

\section{ACKNOWLEDGMENTS}

Thanks go to Andalas University for providing the support needed to complete this study.

\section{REFERENCES}

[1] BNPB, Perka BNPB No. 3 year 2012 on Regional Capacity Assessment Guide in Disaster Management, 2012, p. 23.

[2] Suryadi., Yuliza M., Chandranata A., and Yulindon., Landslides Early Warning System With GSM Modem Based On Microcontroller Using Rain, Soil Shift And Accelerometer Sensors. International Journal of GEOMATE, Vol. 19, No. 71, 2020, pp. 137-144.

[3] Paulus, Slope Stability Manual and Avalanche Handlers, Bandung, Vol 4, 2019.

[4] Akmam, Amir H. and Putra A., Identification of Cashing Fields Using Methods Geolistric Resistance Type of Slide Raw Area in City Padang and Agam District, West Sumatera.

[5] Manrulu R. and Nurfalaq A., Study of the field of derailment as a first step in landslide disaster mitigation, Universitas Cokroaminoto Palopo, 2016, pp. 190-196.

[6] Zakaria Z., Soil Slope Stability Analysis, Geological Engineering Faculty of Geological Engineering, Padjajaran University, Bandung.

[7] Sugito, Irayani Z. and Jati I.P., Landslide Derailment Investigation Using Geoelectric Methods, Berk Fis, vol. 13, no. 2, 2010, pp. 4954.

[8] Furuya T. and Jiang J.C., Determination Of Slip Surfaces In Fracture Zone Landslides Using Oriented Borehole Core Samples. International Journal of GEOMATE, Vol. 8, No. 1, 2015, pp. 1151-1158.

[9] Li, S.H., Wu, L.Z. and Luo, X.H., A Novel Method for Locating the Critical Slip Surface of
A Soil Slope, J. of Engineering Applications of Artificial Intelligence, Vol. 94, No. 2020, 2020, pp. 1-15.

[10] Hakam A., Slope Stability and Ground Retaining Wall, Andalas University Press, 2010.

[11] Shinoda M., Seismic Stability And Displacement Analyses of Earth Slopes Using Non-Circular Slip Surface, J. of Soils and Foundation., Vol. 55, No. 2, 2015, pp. 227-241.

[12] Zhu Y., Peng X., Tan K., Shi M., Hong Y., and Wang Y., Searching for Slip Surface of Disturbed Slope Based on Logistic Function, J. of Shock and Vibration, Vol. 2020, 2020, pp. 19.

[13] Liu S.Y., Shao L.T., and Li H. J., Slope Stability Analysis Using The Limit Equilibrium Method And Two Finite Element Methods, J. of Computers and Geotechnics, Vol. 63, 2015, 2014, pp. 291-298.

[14] Fellenius W., Calculation of the stability of earth dams, Proceedings of the second congress of large dams, Vol. 4, 1936, pp. 445-463.

[15] Bishop A.W., The Use of the Slip Circle in the Stability Analysis of Slopes, Geotechnique, Vol. 5, No. 1, 1955, pp. 7-17.

[16] Morgenstern N.R. and Price V.E., The Analisys of the Stability of General Slip Surfaces, 1965, pp 79-93.

[17] Spencer E., A Method of Analisys of the Stability Embankments Assuming Parallel Inter-Slice Forces, Geotechnique, Vol. 17, 1967, pp. 11-26.

[18] Sarma S.K., Stability Analysis Of Embankments And Slopes, J. of Geotechnique, Vol. 23, No. 3, 1973, pp. 423-433.

[19] Yang Y., Wu W., and Zheng H., Searching For Critical Slip Surfaces of Slopes Using Stress Fields by Numerical Manifold Method, J. of Rock Mechanics and Geotechnical Engineering, 2020, pp. 1674-7755.

[20] Chen X. and Wang H., Slope Failure Of Noncohesive Media Modelled with the Combined Finite-Discrete Element Method, Applied Science, Vol. 9, No. 3, 2019, pp. 1-13.

[21] Xu G et al., Determination Methods of A Tuff Landslide Slip-Surface, Proceedin International Conference, 2019, pp K1-1 - K1-8.

Copyright (C) Int. J. of GEOMATE. All rights reserved, including the making of copies unless permission is obtained from the copyright proprietors. 